Original article

\title{
COMPUTED TOMOGRAPHY DENSITOMETRY OF FEMORAL DEFECT HEALING AFTER IMPLANTATION OF CALCIUM PHOSPHATE BIOCERAMICS IN RATS
}

\author{
O. V. KORENKOV \\ Department of Human Anatomy, Medical Institute of Sumy State \\ University, Ukraine
}

\begin{abstract}
Summary
Korenkov, O. V., 2016. Computed tomography densitometry of femoral defect healing after implantation of calcium phosphate bioceramics in rats. Bulg. J. Vet. Med., 19, No 2, 87-95.

The aim of this study was to investigate the healing process of diaphyseal femoral bone defects of rats after implantation of osteoplastic material "easy-graft ${ }^{\mathrm{TM}}$ CRYSTAL" in their cavity The dynamics of reparative osteogenesis was evaluated by computed tomography and optical bone density was expressed in Hounsfield units. Starting from the $30^{\text {th }}$ day of the experiment, emergence and radiological signs of subsequent bone tissue growth, and the gradual disappearance of the defect with simultaneous increase of absolute and relative density of regenerate were found. At $15-30^{\text {th }}$ day, we found a clear visualisation of the defect due to the prevalence of maternal bone optical density $(1766.5 \pm 38$ $\mathrm{HU}$ and $1761.1 \pm 41 \mathrm{HU})$ over the optical density of the implantation site $(1059.5 \pm 44 \mathrm{HU}$ and $1354.9 \pm 46 \mathrm{HU})$. On the $60^{\text {th }}$ day the defect disappeared through as the absolute osteoplastic material density of the implantation site $(1668.1 \pm 53 \mathrm{HU})$ approached that of the maternal bone $(1788.8 \pm 29$ $\mathrm{HU})$. On the $120^{\text {th }}$ day of the experiment, the regenerate optical density $(1883.5 \pm 28 \mathrm{HU})$ exceeded the absolute optical density of the maternal bone $(1792.2 \pm 56 \mathrm{HU})$ with simultaneous absence of full recovery of the original shape of bone and rarefaction of the maternal bone throughout the term of the experiment.
\end{abstract}

Key words: bone, computed tomography, Hounsfield units, osteoplastic material easygraft $^{\mathrm{TM}}$ CRYSTAL, reparative osteogenesis

\section{INTRODUCTION}

One of the most important problems that orthopaedic physicians face in their practice is bone defects regeneration. The high frequency of occurrence of bone defects dictate the need to find tools that would ensure their full recovery. Transplantation of bone tissue, which is used to combat this pathology has a long history and has achieved a considerable success. However, despite this, the used auto- and xenografts still have serious drawbacks. Thus, xenogeneic material has strong antigenic activity, restructuring process is much slower compared to other osteoplastic materials. In addition, when bone tissue of animal origin is used, there is a risk 
of transmission of infectious diseases. In turn, the use of bone autografts is greatly limited in the medical practice because of the additional injuries, failure to use them in case of large bone defects, prolongation of operation, the possibility of complications (fractures in the donor site, nerve damage, cosmetic defects, prolapse of bone defects), the inability of the workpiece and preservation of autogenous plastic material. As a result, in recent years there has been a growing interest in calcium phosphate osteoplastic materials to replace bone tissue in the clinical practice. The similarity of their chemical structure with that of bone tissue and inertness to biological tissues makes possible to widely use them to replace the lost bone tissue (Germanov et al., 2006). In addition, synthetic nature of calcium phosphate material guarantees safety in practice preventing the risk of infection, and clinical trials consistently demonstrate exceptional biocompatibility of the materials (Becker, 2006).

It is known that to replace bone defects tricalcium phosphate and hydroxyapatite, which have different resorption in the area of implantation are most commonly used (Köhli, 2012). Physicians take into consideration this ability when using implants in each clinical situation. Thanks to the fact that tricalcium phosphate undergoes resorption faster than hydroxyapatite, it is possible to combine them in a biphasic osteoplastic medication in order to regulate the process of resorption in the area of implantation through the changes of the ratio of its components (Daculsi et al., 2003; LeGeros et al., 2003; Malard et al., 2005; Jensen et al., 2009). Today it is believed that the optimal ratio of hydroxyapatite and tricalcium phosphate as part of biphasic osteoplastic material is $60 \%$ to $40 \%$ (Ruffieux \& Kohli, 2011).
One of these relatively new substances is easy-graft $^{\mathrm{TM}}$ CRYSTAL, which was developed in Switzerland by the company Degradable Solutions AG. With the help of the study of $\beta$-tricalcium phosphate phase of the easy-graft product, it was found that after its implantation into the bone defect it undergoes resorption and replacement by the bone tissue during 6-7 months (Glaser, 2009; Pavlenko et al., 2012). At the same time advertising information and scientific and clinical studies indicate that biphasic osteoplastic easy-graft $^{\mathrm{TM}}$ CRYSTAL preparation undergoes a partial resorption mainly due to $\beta$-tricalcium phosphate, and hydroxyapatite thus remains in the area of the defect for a longer period, ensuring prevention of atrophy and preservation of bone tissue volume (Zafiropoulos et al., 2007; Lan Levengood et al., 2010). However, these conclusions were made from histological studies on the jaws, flat and spongy bones, but there is no information on the impact of easy-graft ${ }^{\mathrm{TM}}$ CRYSTAL on healing of compact bone tissue defect (Cordaro et al., 2008; Froum et al., 2008; Lee et al., 2008; Pavlenko et al., 2013). Despite the fact that pathoanatomical diagnosis was, is and probably will be the most accurate option, in the clinical practice a practitioner does not always have a possibility to take a bone specimen for histological analysis. At the same time radiographic methods are very often used by orthopaedists and traumatologists for evaluation of the healing of fractures and bone defects. Of the latter, computed tomography is characterised by the highest level of accuracy achieved through obtaining layered images of different parts of bone that cannot be done with conventional radiography (Rathnayaka et al., 2011).

The aim of this study was to investigate the dynamics of reparative osteo- 
genesis, biodegradation, integration of easy-graft ${ }^{\mathrm{TM}}$ CRYSTAL into the defect of compact bone tissue (diaphysis) of femoral bones by computed tomography.

\section{MATERIALS AND METHODS}

The experiment was performed on 24 white laboratory male rats, 8 months of age, with a body weight of $250 \pm 10 \mathrm{~g}$ with the approval of the Institutional Bioethics Committee. The surgical intervention was performed under general ketamine anaesthesia $(0.3-0.5 \mathrm{~mL} / \mathrm{kg})$ in aseptic conditions. With the help of spherical cutter (diameter of $2.5 \mathrm{~mm}$ ) at low speed and with cooling, a defect to the medullary channel was reproduced in femoral bone diaphyses, which were filled with osteoplastic material easy-graft ${ }^{\mathrm{TM}}$ CRYSTAL (Degradable Solutions AG, Switzerland reg. No 2008/03310) without rigid fixation. The preparation is produced as a syringe with granules and a vial with an organic solvent BioLinker ${ }^{\mathbb{R}}$. The granules consist of $40 \% \beta$-tricalcium phosphate and
$60 \%$ hydroxyapatite, and BioLinker $\left.{ }^{(}\right)$of water and N-methyl-2-pyrrolidone (NMP). Each granule of the material (Fig. 1) is covered with thin $(10 \mu \mathrm{m})$ polymer of polylactic and polyglycolic acid (PLGA), which is capable of resorption (Ruffieux \& Kohli, 2011; Köhli, 2012).

Before the injection of the material into the defect the granules were soaked in the BioLinker ${ }^{\circledR}$ liquid, which temporarily softened the outer shell of granules and provided their bonding. In this case the material gained a lamellar mass consistency, which was easy to model in the shape of the defect. After injecting the material into the bone defect it was soaked with blood, which ensured the removal of BioLinker $^{\circledR}$, and the material began to harden within minutes. Thus, a stable porous mass with microcells inside the granules the size from 1 to $10 \mu \mathrm{m}$ and macrocells between separate granules was formed.

On the $15^{\text {th }}, 30^{\text {th }}, 60^{\text {th }}$ and $120^{\text {th }}$ day the animals were fixed on the preparation table at four limbs belly down and we research on femoral bones implanted with

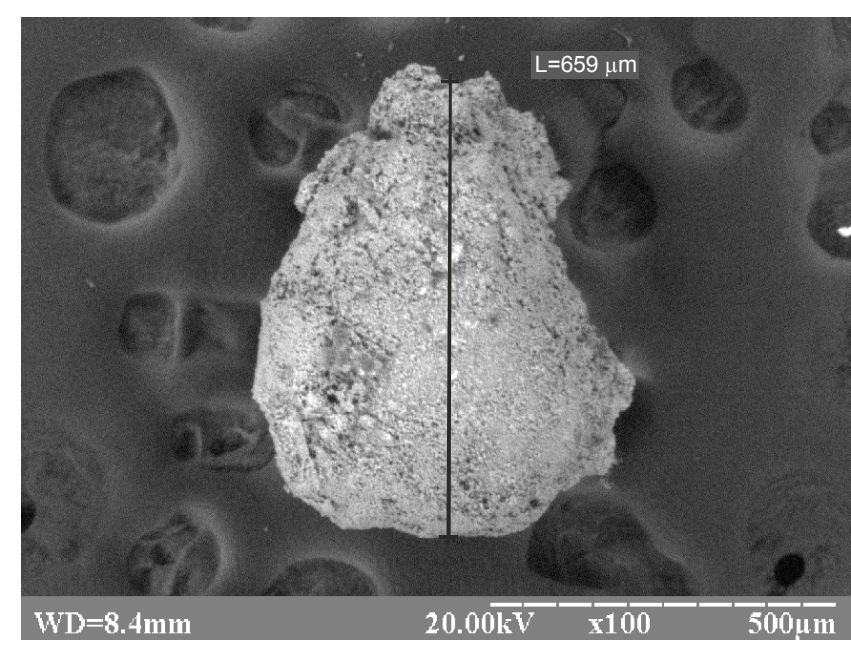

Fig. 1. Electron microscopy scan of a granule of the osteoplastic material easy-graft CRYSTAL with size of $659 \mu \mathrm{m}$. 
Computed tomography densitometry of femoral defect healing after implantation of calcium phosphate...

easy-graft $^{\mathrm{TM}}$ CRYSTAL was conducted on 16-section spiral computed tomograph Toshiba Activion (Toshiba, Japan) to investigate the dynamics of biodegradation of the implant, as well as expression of postoperative complications due to the presence or absence of rarefaction of maternal bone. The optical density of the regenerate with the implant and the adjacent cortical layer of the maternal bone was measured in Hounsfield units. To evaluate the difference of these indicators, we determined the relative optical density of the regenerate by the formula:

$$
R O D R=\frac{A O D R(H U)}{A O D B(H U)} \times 100 \%
$$

where RODR - relative optical density of the regenerate (\%); AODR - absolute optical density of the regenerate; AODB absolute optical density of the area adjacent to the maternal bone defect. The resulting digital values were processed statistically to calculate the arithmetic mean and its standard error. The significance of differences between comparable indicators was evaluated using Student $t$-test using statistical computer programme MS Excel XP. The differences were considered significant at $\mathrm{P}<0.05$.

\section{RESULTS}

On the $15^{\text {th }}$ day computed tomography study demonstrated a well visualised area of the femoral bone defect with distinct edges of the maternal bone adjacent to the implantation site and no signs of rarefaction. In the cavity of the defect and bone marrow space shadow of osteoplastic material with a density (visually) significantly lower than the maternal bone could be seen. Due to this in the computed tomogram we could clearly trace the boundary between the edges of the defect and osteoplastic material that had a heterogeneous texture and oval shape (Fig. 2). Measurement of the optical density revealed that for the site of implantation of

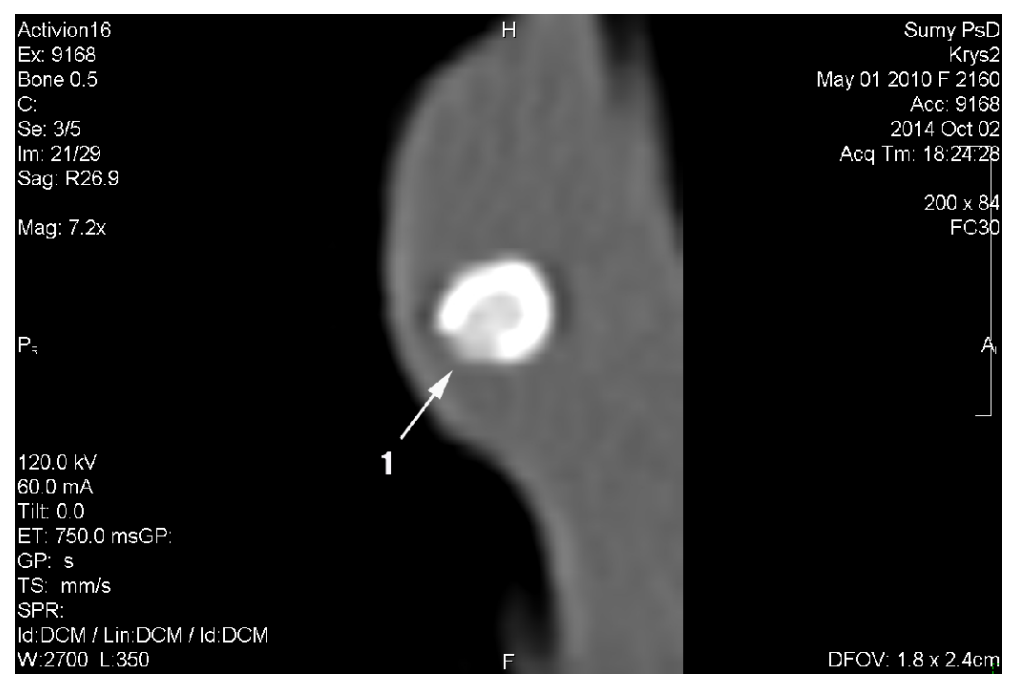

Fig. 2. Computed tomography of the right rat femoral bone on the $15^{\text {th }}$ day after the implantation of easy-graft CRYSTAL. Osteoplastic material with regenerate tissue-specific structure in the cavity of the cortical bone defect and medullary space (1). 
Table 1. Absolute and relative optical density of bone regenerate with osteoplastic material in rats (mean \pm SEM; $n=6$ )

\begin{tabular}{lcccc}
\hline \multirow{2}{*}{ Measurement area } & \multicolumn{4}{c}{ Post implantation day } \\
\cline { 2 - 5 } & 15 & 30 & 60 & 120 \\
\hline $\begin{array}{l}\text { Absolute optical density of } \\
\text { regenerate (HU) }\end{array}$ & $1059.5 \pm 44$ & $1354.9 \pm 46$ & $1668.1 \pm 53$ & $1883.5 \pm 28$ \\
$\begin{array}{l}\text { Absolute optical density of } \\
\text { maternal bone (HU) }\end{array}$ & 59.97 & 76.93 & 93.25 & 105 \\
$\begin{array}{l}\text { Relative optical density of } \\
\text { regenerate (\%) }\end{array}$ & & $1761.1 \pm 41$ & $1788.8 \pm 29$ & $1792.2 \pm 56$ \\
\hline
\end{tabular}

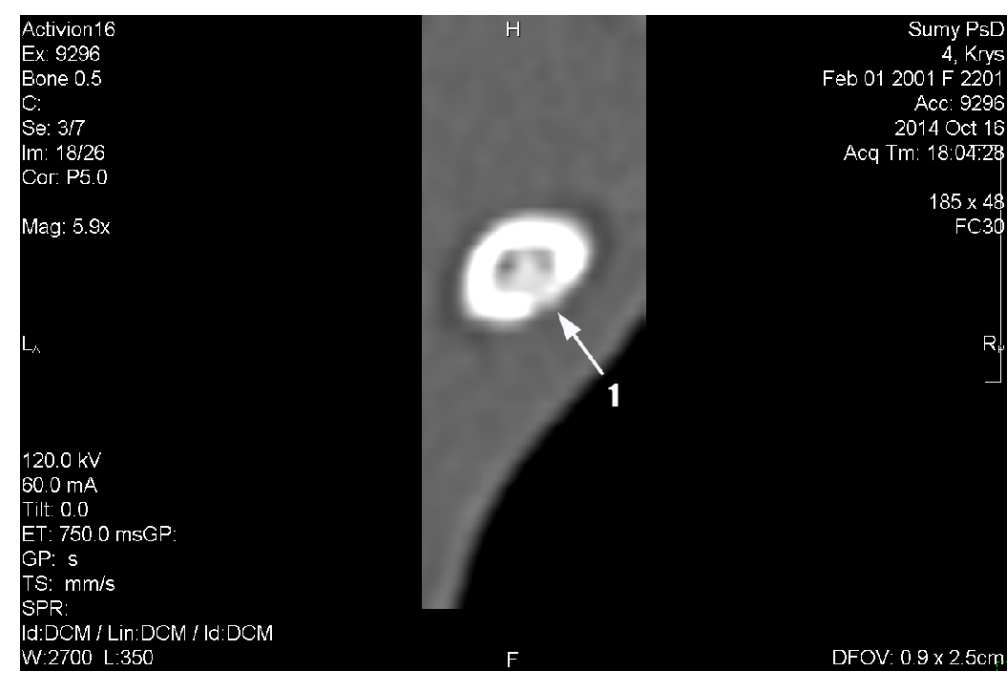

Fig. 3. Computed tomography of the rat femur on the $30^{\text {th }}$ day after the implantation of easy-graft CRYSTAL. The defect of the cortical layer with osteoplastic material and tissue-specific structures of regenerate, whose density is visually lower than the edges of the adjacent maternal bone (1).

osteoplastic material it was $1059.5 \pm 44$ $\mathrm{HU}$, whereas for the maternal bone adjacent to the site of injury $-1766.5 \pm 38 \mathrm{HU}$. Hence, the relative optical density of the site of implantation with the above indicators was $59.97 \%$ (Table 1 ).

On the $30^{\text {th }}$ day of the experiment computed tomography study found a reduction of the size of the defect compared to the previous period of observation. However, the area of the defect with the implanted osteoplastic material still appe- ared of a lighter colour than the maternal bone (Fig. 3). Consequently, the boundary between them was still well traced, but less clearly than on the $15^{\text {th }}$ day of the experiment. The maternal bone did not show signs of rarefaction, and the osteoplastic material with components of the regenerate did not have uniform consistency with areas of enlightenment and eclipse. The optical density of the site of the defect increased to $27.88 \%$, and for the adjacent maternal bone remained prac- 
Computed tomography densitometry of femoral defect healing after implantation of calcium phosphate...

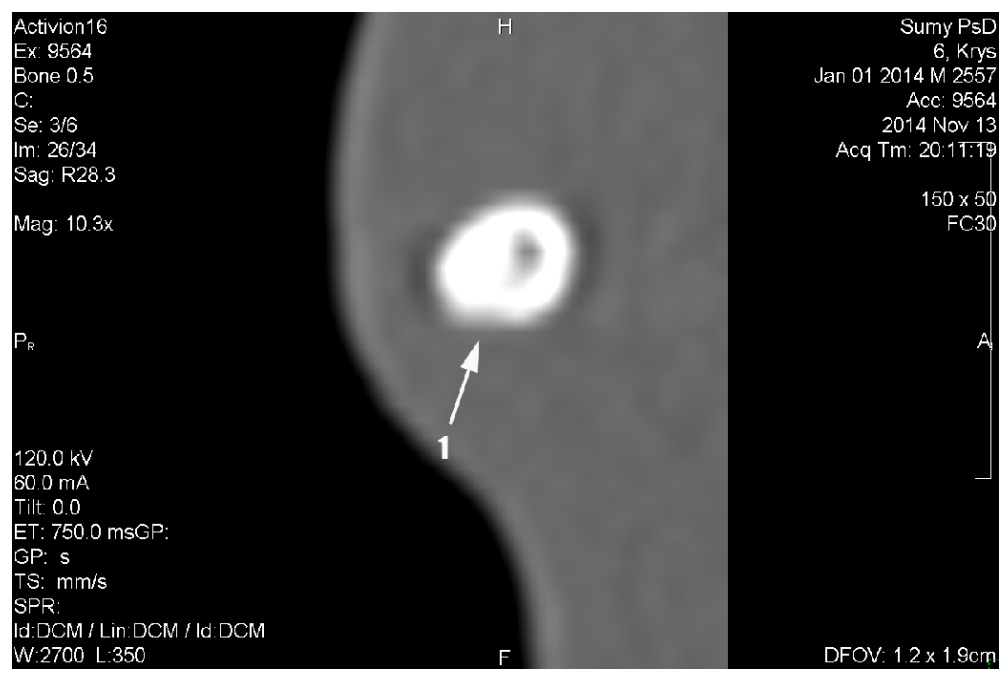

Fig. 4. Computed tomography of the rat femur on the $60^{\text {th }}$ day after the implantation of easy-graft CRYSTAL. Restored density on the site of defect with a slight indentation in the outer layer and endosteal callus with remnants of osteoplastic material in the medullary canal (1).

tically unchanged compared to the $15^{\text {th }}$ day experiment $(1354.9 \pm 46 \mathrm{HU}$ and $1761.1 \pm 41 \mathrm{HU}$ respectively). Based on these indicators, the relative optical density of the implantation site of osteoplastic material also increased to $76.93 \%$ (vs $59.97 \%$ on the $15^{\text {th }}$ day of the experiment; Table 1).

On the $60^{\text {th }}$ day the CT scan exhibited a further reduction of the size of the defect compared to the $30^{\text {th }}$ day of the experiment. In some cases, in the central part of the defect there still remained a small area of low density compared to the surrounding maternal bone edges. In other cases, a visual process of merging in density of the site of the defect with the maternal bone and simultaneous presence of small holes in the outer layer of bone at the level of implantation of the osteoplastic material could be observed. In addition, in the medullary canal there were remnants of osteoplastic material with considerable in size endosteal callus (Fig. 4).
For the site of easy-graft ${ }^{\mathrm{TM}}$ CRYSTAL implantation, the optical density was $1668.1 \pm 53 \mathrm{HU}$, and for the adjacent maternal bone $-1788.8 \pm 29 \mathrm{HU}$, which was by $23.11 \%$ more in the first and practically unchanged in the second case compared to the $30^{\text {th }}$ day of experiment (Table 1). Due to the increased optical density, relative density of the osteoplastic material at the implantation site was also increased to $93.25 \%$ (against $76.93 \%$ on the $30^{\text {th }}$ day of the experiment).

On the $120^{\text {th }}$ day of the experiment computed tomography found a complete restoration of the bone cortical layer at the level of the defect, whose density and shape merged with adjacent maternal bone. The only thing that revealed the place of the past trauma was the presence of residues of osteoplastic material in the medullary canal with significantly dense endosteal callus of round or oval shape (Fig. 5). The optical density of osteoplastic material was $1883.5 \pm 28 \mathrm{HU}$ at the implantation site, and for the adjacent 


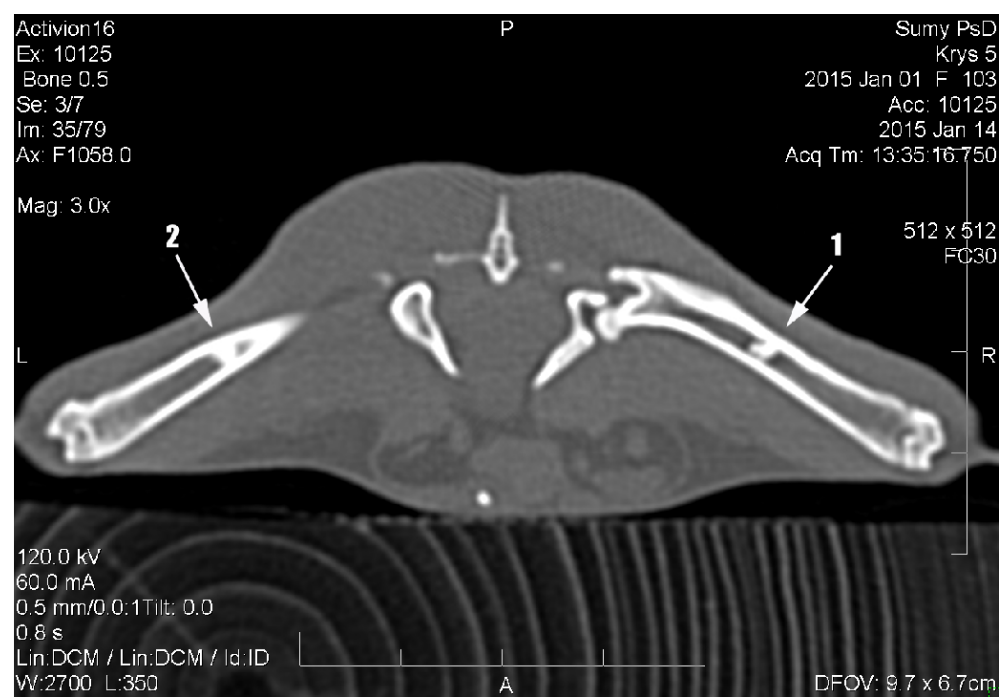

Fig. 5. Computed tomography of the rat femur on the $120^{\text {th }}$ day after the implantation of easy-graft CRYSTAL. Restored shape and density of cortical layer of right (1) and left (2) femur with the preservation of endosteal callus with remnants of osteoplastic material.

maternal bone $-1792.2 \pm 56 \mathrm{HU}$, i.e. by $12.91 \%$ more than in the first and practically unchanged in the second case compared to the $60^{\text {th }}$ day of experiment (Table 1). Due to the fact that optical density of osteoplastic material became greater than the density of the surrounding maternal bone, the relative optical density at the implantation site exceeded $100 \%$ and was $105 \%$.

\section{DISCUSSION}

The research by computed tomography of of femoral bone diaphyseal defects in rats after implantation of the osteoplastic material easy-graft ${ }^{\mathrm{TM}}$ CRYSTAL established that the latter had a high biocompatibility, as evidenced by the absence of rarefaction of the maternal bone throughout the entire experiment. These results are consistent with the data of most researchers (Ruffieux \& Kohli, 2011; Pavlenko et al.,
2013; Schmidlin et al., 2013). Additionally, the implanted easy-graft ${ }^{\mathrm{TM}}$ CRYSTAL granules were placed both in the defect area at the level of cortical bone and into the medullary canal during the study. By the $15^{\text {th }}-30^{\text {th }}$ day of the experiment the absolute density of maternal

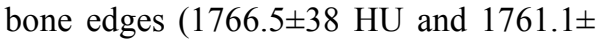
$41 \mathrm{HU})$ was considerably greater than that of the implantation site $(1059.5 \pm 44 \mathrm{HU}$ and $1354.9 \pm 46 \mathrm{HU})$, which ensured its clear visualisation on CT scans. On the sixtieth day of the experiment there was no recovery of the geometric shape of the bone cortical layer, but disappearance of visualisation of defect area as its absolute density (1668.1 $\pm 53 \mathrm{HU})$ approached that of the maternal bone (1788.8 $\pm 29 \mathrm{HU})$. All this indicates that the amount of bone regenerate and the degree of its mineralisation were greater than in the previous terms of experiment. On the $120^{\text {th }}$ day of the experiment the optical density of the regenerate even exceeded the absolute 
optical density of the maternal bone that according to the densitometry study can be interpreted as full restoration of the integrity of the bone (Table 1).

In experimental defects of the frontal and parietal bones of rabbits, Schmidlin et al. (2013) also observed growth of regenerate bone tissue directly on the surface of easy-graft ${ }^{\mathrm{TM}}$ CRYSTAL granules, which were subjected to gradual resorption. However, the percentage of bone tissue on the $4^{\text {th }}$ and $16^{\text {th }}$ week after implantation of easy-graft CRYSTAL was relatively small $(20.16 \pm 5.27 \%$ and $22.40 \pm 5.54 \%$ ) and most importantly, without significant difference between them. According to the authors, one of the factors that could affect this is the low rate of resorption of osteoplastic material. The latter, according to Lindgren et al. (2010), may be due to the fact that the biphasic osteoplastic material undergoes resorption by $\beta$-tricalcium phosphate phase of the drug, whereas hydroxyapatite does not dissolve for a long time and keeps its occupied area. According to the results of this study the size of the defect site decreases with each subsequent observation period and its absolute and relative density increased, indicating increased amount and mineralisation of the newly formed bone tissue of regenerate, which replaced osteoplastic material. On the $120^{\text {th }}$ day radiologically there was a complete recovery of cortical bone, as evidenced by the absence of deformation on its outer surface, and levelling of the density with the maternal bone. However, in the last period of the experiment there was no complete restoration of the geometric shape of the bone, as endosteal callus with the remnants of osteoplastic material still remained in the medullary canal.

In conclusion, the revealed CT imaging dynamics of healing of the femoral bone defect showed a high biocompatibility of the polylactide-coated biphasic calcium phosphate easy-graft ${ }^{\mathrm{TM}}$ CRYSTAL, its good integration with bone tissue, as well as the ability of the osteoplastic material to undergo resorption within a period of more than 4 months.

\section{REFERENCES}

Becker, S., 2006. Osteopromotion by a B-TCP. Bone marrow hybrid implant for use in spine surgery. Spine, 31, 11-17.

Cordaro, L., D. D. Bosshardt, P. Palattella, W. Rao, G. Serino \& M. Chiapasco, 2008. Maxillary sinus grafting with Bio-Oss or Straumann Bone Ceramic: histomorphometric results from a randomized controlled multicenter clinical trial. Clinical Oral Implants Research, 19, 796-803.

Daculsi, G., O. Laboux, O. Malard \& P. Weiss, 2003. Current state of the art of biphasic calcium phosphate bioceramics. Journal of Materials Science: Materials in Medicine, 14, 195-200.

Froum, S. J., S. S. Wallace, S. C. Cho, N. Elian \& D. P. Tarnow, 2008. Histomorphometric comparison of a biphasic bone ceramic to anorganic bovine bone for sinus augmentation: 6- to 8-month postsurgical assessment of vital bone formation. A pilot study. International Journal of Periodontics \& Restorative Dentistry, 28, 273-281.

Germanov, V. G., G. M. Kovalersky, Z. A. Cherkashena \& V. A. Semenov, 2006. Osteoplastic surgery: From bone transplant to the modern biocomposite materials. Medical Assistance Available, 4, 16-19.

Glaser, R., 2009. Rehabilitation mit 3D Planung und Kieferkammerhalt. Zahnarzt, 4, 29-31.

Jensen, S. S., M. M. Bornstein, M. Dard, D. D. Bosshardt \& D. Buser, 2009. Comparative study of biphasic calcium phosphates with different ha/ tcp ratios in mandibular bone defects. A longterm histomorphometric study in minipigs. Journal of Biomedical 
Materials Research. Part B, Applied Biomaterials, 90, 171-181.

Köhli, M., 2012. Evaluation of moldable in situ hardening bone graft substitute in an animal model. Implants Extra, 1, 5-34.

Lan Levengood, S. K., S. J. Polak, M. B. Wheeler, A. J. Maki, S. Clark, R. D. Jamison \& A. J. Wagoner-Johnson, 2010. Multiscale osteointegration as a new paradigm for the design of calcium phosphate scaffolds for bone regeneration. Biomaterials, 31, 3552-3563.

Lee, J. H., U. W. Jung, C. S. Kim, S. H. Choi \& K. S. Cho, 2008. Histologic and clinical evaluation for maxillary sinus augmentation using macroporous biphasic calcium phosphate in human. Clinical Oral Implants Research, 19, 767-771.

LeGeros, R. Z., S. Lin, R. Rohanizaden, D. Mijares \& J. P. LeGeros, 2003. Biphase calcium phosphate bioceramics: Preparation, properties and applications. Journal of Materials Science: Materials in Medicine, 14, 201-209.

Lindgren, C., M. Hallman, L. Sennerby \& R. Sammons, 2010. Back-scattered electron imaging and elemental analysis of retrieved bone tissue following sinus augmentation with deproteinized bovine bone or biphasic calcium phosphate. Clinical Oral Implants Research, 21, 924-930.

Malard, O., J. Guicheux, J. M. Bouler, O. Gautier, C. Beauvillain de Montreuil, E. Auguado, P. Pilet, R. LeGeros \& G. Daculsi, 2005. Calcium phosphate scaffold and bone marrow for bone reconstruction in irradiated area: A dog study. Bone, 36, 323330.

Pavlenko, A. V., R. R. Iluk, V. F. Tokarsky \& A. Shterenberg, 2012. Clinical evaluation of a new osteoconductive material «easygraft ${ }^{\mathbb{B}} \gg$ with sinus lift and its effect on the regeneration of bone tissue. Modern Dentistry, 2, 112-118.
Pavlenko, A. V, V. F. Tokarsky, G. B. Prots, V. G. Klimentev \& A. Shterenberg, 2013. New biphasic bone intriguing materials «easy-graft ${ }^{\circledR}$ CRYSTAL» based on $\beta$ tricalcium phosphate with bone defects. Modern Dentistry, 1, 89-92.

Rathnayaka, K., T. Sahama, M. A. Schuetz \& B. Schmutz, 2011. Effects of CT image segmentation methods on the accuracy of long bone 3D reconstruction. Medical Engineering \& Physics, 33, 226-233.

Ruffieux, K. \& M. Kohli, 2011. Build-up of bone tissue. Materials research and clinical application instructions for easy-graft ${ }^{\circledR}$ materials and easy-graft ${ }^{\circledR}$ CRYSTAL, Company "Stam", Kiev, pp. 20-42.

Schmidlin, P. R., F. Nicholls, A. Kruse, R. A. Zwahlen \& F. E. Weber, 2013. Evaluation of moldable, in situ hardening calcium phosphate bone graft substitutes. Clinical Oral Implants Research, 24, 149-157.

Zafiropoulos, G. G., O. Hoffmann, A. Kasaj, B. Willershausen, O. Weiss \& T. E. van Dyke, 2007. Treatment of intrabony defects using guided tissue regeneration and autogenous spongiosa alone or combined with hydroxyapatite/beta-tricalcium phosphate bone substitute or bovine-derived xeno-graft. Journal of Periodontology, $\mathbf{7 8}$, 2216-2225.

Paper received 08.05.2015; accepted for publication 15.06.2015

\section{Correspondence:}

Olexiy V. Korenkov Department of Human Anatomy, Medical Institute of Sumy State University, 31 Sanatorna str 40000 Sumy, Ukraine phone.: +38066-843-65-03, e-mail: korenkov-alexsey@mail.ru 